\title{
Maternal and newborn seroprevalence of Hepatitis E virus at
}

\section{Medani Hospital, Sudan [version 1; peer review: 3 approved}

\section{with reservations]}

\author{
Reem Eltayeb1, Gasim I. Gasim², Elhassan M. Elhassan (iD3, Halla Abdullahi4, \\ Duria A. Rayis ${ }^{4}$, Ishag Adam (iD 4 \\ ${ }^{1}$ Khartoum College of Medical Sciences, Khartoum, 10995, Sudan \\ ${ }^{2}$ College of Medicine, Qassim University, Qassim, 52571, Saudi Arabia \\ ${ }^{3}$ Faculty of Medicine, University of Gezira, Wad Medani, 22461, Sudan \\ ${ }^{4}$ Faculty of Medicine, University of Khartoum, Khartoum, 11115, Sudan
}

V1 First published: 16 Sep 2015, 4:823

https://doi.org/10.12688/f1000research.7041.1

Latest published: 16 Sep 2015, 4:823

https://doi.org/10.12688/f1000research.7041.1

\section{Abstract}

Hepatitis E virus (HEV) infection can lead to adverse maternal and perinatal outcomes and is a risk for mortality in pregnant women. There are few published data on the seroepidemiology of HEV infection in pregnant women and none are available from Sudan specifically. A cross-sectional study was conducted to investigate the seroepidemiology of anti-HEV Immunoglobulin G (IgG) antibodies in mothers and newborns in Medani Hospital, Sudan. Sociodemographic, clinical and obstetric characteristics of the women were gathered using questionnaires. Anti-HEV IgG antibodies were investigated in the paired maternal and newborn sera using an enzyme-linked immunoassay (ELISA). Two hundred and nine women were enrolled to the study. The mean (SD) of their age, parity and gestational age was $27.5(5.5)$ years, $2.2(1.5)$ and 38.8 (1.8) weeks, respectively. Out of these 209, 25 (12.5\%) women had a positive result for anti-HEV IgG and two (1.0\%) newborns had a positive result for anti-HEV IgG.In logistic regression none of the investigated factors (age, parity, gestational age, residency and education) were associated with anti-HEV IgG seropositivity. There is a high seroprevalence of HEV among pregnant women in central Sudan regardless of their age, parity and gestational age. Optimal preventive measures against HEV infection should be employed.

Keywords

Pregnancy, vertical transmission, HEV, newborn, Sudan

\section{Open Peer Review \\ Approval Status ? ? \\ $1 \quad 2 \quad 3$

version $1 ?$ ? ? \\ 1. Stephanie M. Borchardt, Wisconsin \\ Department of Health Services, Madison, USA \\ 2. Anna Maria Spera, University of Naples \\ Federico II, Naples, Italy \\ Vincenzo Bianco, University of Naples \\ Federico II, Naples, Italy \\ 3. Shalini Rajaram, University College of Medical Sciences, New Delhi, India \\ Any reports and responses or comments on the article can be found at the end of the article.}


Corresponding author: Ishag Adam (ishagadam@hotmail.com)

Competing interests: No competing interests were disclosed.

Grant information: The author(s) declared that no grants were involved in supporting this work.

Copyright: @ 2015 Eltayeb R et al. This is an open access article distributed under the terms of the Creative Commons Attribution License, which permits unrestricted use, distribution, and reproduction in any medium, provided the original work is properly cited. Data associated with the article are available under the terms of the Creative Commons Zero "No rights reserved" data waiver (CC0 1.0 Public domain dedication).

How to cite this article: Eltayeb R, Gasim GI, Elhassan EM et al. Maternal and newborn seroprevalence of Hepatitis E virus at Medani Hospital, Sudan [version 1; peer review: 3 approved with reservations] F1000Research 2015, 4:823

https://doi.org/10.12688/f1000research.7041.1

First published: 16 Sep 2015, 4:823 https://doi.org/10.12688/f1000research.7041.1 


\section{Introduction}

Hepatitis E virus (HEV) is a single-stranded RNA virus and an emerging infectious agent where it can cause acute viral hepatitis worldwide with estimated 20 million cases of HEV infection occur globally and 70000 deaths (Aggarwal \& Gandhi, 2010; Rein et al., 2012). Due to hormonal and immunological changes, pregnant women are more prone to have severe form of HEV infections where there is increasing evidence that HEV is an important contributor to maternal and perinatal morbidity and mortality, especially in the developing countries (Ahmed et al., 2008; Bose et al., 2011; Bose et al., 2014; Kumar et al., 2001; Navaneethan et al., 2008; Ornoy \& Tenebaum, 2006; Rayis et al., 2013). In previous studies, Stoszek et al. (2006) and Patra et al. (2007) reported prevalence rates of $84.3 \%$ and $60 \%$ of anti-HEV antibodies among pregnant women in Egypt and India, respectively.

In Sudan, a high mortality rate was reported among pregnant women in an outbreak of HEV in Darfur and in eastern Sudan (Boccia et al., 2006; Rayis et al., 2013). In spite of this there are no published data on the seroprevalence of anti-HEV IgG in Sudan and screening of HEV is not part of the antenatal care programme. Research on the seroprevalence of HEV is of paramount importance for health policy makers as well as for the practicing clinicians and it will yield data necessary for developing preventive measures. This study was conducted to determine the seroprevalence of anti-HEV IgG among a population of pregnant women and their newborns in Medani, Sudan.

\section{Materials and methods}

A cross-sectional study was conducted at the delivery ward of Medani Maternity Hospital, Sudan during the period of March 2013. Medani Hospital is a tertiary care hospital in central Sudan, located in Al Gezira state which is the second largest state in Sudan. Women with a singleton pregnancy were approached to be enrolled to the study. Mothers who experienced stillbirths and those who had been diagnosed with diabetes or hypertension were excluded from the current study. After signing an informed consent form, sociodemographic, medical and obstetric characteristics were gathered using a questionnaire that was applied in the local language (Arabic; see Supplementary file 1 for sample questionnaire). A convenience sampling method was used where consecutive eligible women were recruited every day until the total desired sample size was achieved (206). The sample size of 206 women was calculated based on a 2-sided hypothesis test using Epiinfo software (Centre for Disease Control, USA; version 6) that yielded $80 \%$ power and a confidence interval of $95 \%$ with $10 \%$ of women expected to have incomplete data or samples.

Body mass index (BMI) was calculated by maternal weight and height that were measured. Five millilitres of blood was collected from each woman along with the corresponding infants' umbilical cord. The umbilical cords were stored in plain tubes and all samples were labelled and kept at room temperature for 30 minutes, centrifuged at $2000 \mathrm{rpm}$ for 10 minutes to separate blood components. Serum was stored at -20 degrees until analyzed for anti-HEV IgG using specific antibody profiles using $\mathrm{HEV} \mathrm{IgG-specific} \mathrm{ELISA}$ (Euroimmun, Lübeck, Germany).

\section{Statistics}

Data were entered in computer using SPSS software (IBM, UK; version 16) for Windows. Statistics were described as mean (SD) for continuous data and as frequency and percentages (\%) for categorized data. $T$-test and $X^{2}$ were used to compare continuous and categorized data, respectively between women who were seropositive for HEV IgG antibodies and women with a negative result for HEV antibodies. Binary logistic regression was conducted where seropositivity for HEV IgG antibodies was the dependent variable and socio-demographic, clinical characteristics were the independent variable. Odds ratio and $95 \%$ confidence interval were calculated, and $\mathrm{P}$ values of $<0.05$ were considered statistically significant.

\section{Ethics}

Ethical approval was obtained from the Ethical committee of University of Khartoum.

\section{Results}

Two hundred and nine women were enrolled in the study. The mean (SD) of their ages, parities and gestational ages were 27.5 (5.5) years, 2.2 (1.5) and 38.8 (1.8) weeks, respectively. Out of these 209, $25(12.5 \%)$ women had a positive result for anti-HEV IgG and two (1.0\%) newborns whose mothers also had a positive anti-HEV IgG showed a positive result for anti-HEV IgG.

There was no significant difference in the age, parity, education, gestational age, BMI or history of miscarriage between seropositive and seronegative anti-HEV IgG women (Table 1). Likewise, in logistic regression none of these investigated factors were associated with anti-HEV IgG seropositivity (Table 2).

Dataset 1. Raw dataset for Eltayeb et al., 2015 'Maternal and newborn seroprevalence of Hepatitis E virus at Medani Hospital, Sudan'

http://dx.doi.org/10.5256/f1000research.7041.d101652

Socio-demographic, clinical and obstetric characteristics of the women were gathered using questionnaires. Anti-HEV IgG antibodies were investigated in the paired maternal and newborn sera using an enzyme-linked immunoassay (ELISA). Wt=weight (Maternal;kg); Ht=height (Maternal;cm), $\mathrm{Hb}=$ haemoglobin(Maternal; g/dl); birthwt=birthweight (Child; kg); bloodgroup (Maternal): 0=A, 1=B, 2=AB 3=0; HeplgGM=Maternal Hepatitis $E$ IgG, $1=$ positive, $0=$ negative; HeplgGC=Newborn Hepatitis $E \operatorname{lgG}, 1=$ positive, $0=$ negative. Raw data file openable by PSPP, available at https://www.gnu.org/software/pspp/. 


\begin{tabular}{|c|c|c|c|}
\hline Variables & $\begin{array}{l}\text { HEV IgG } \\
\text { seropositive }(n=25)\end{array}$ & $\begin{array}{l}\text { HEV IgG } \\
\text { seronegative }(n=184)\end{array}$ & $\mathbf{P}$ \\
\hline \multicolumn{4}{|l|}{ Mean $(S D)$ of the } \\
\hline Age, years & $27.4(5.0)$ & $27.5(5.6)$ & 0.950 \\
\hline Parity & $2.0(1.9)$ & $2.2(1.4)$ & 0.526 \\
\hline Gestational age, weeks & $38.3(2.5)$ & $38.8(1.7)$ & 0.217 \\
\hline Body mass index, $\mathrm{kg} / \mathrm{cm}^{2}$ & $24.6(2.1)$ & $23.9(2.9)$ & 0.225 \\
\hline Hemoglobin, g/dl & $9.9(1.0)$ & $10.4(1.0)$ & 0.008 \\
\hline \multicolumn{4}{|l|}{ Number (\%) of the } \\
\hline Rural residence & $12(48.0)$ & $101(54.8)$ & 0.300 \\
\hline Education < secondary level & 13(52.0) & $61(33.1)$ & 0.064 \\
\hline History of miscarriage & $7(28.0)$ & $77(41.8)$ & 0.270 \\
\hline
\end{tabular}

Table 2. Univariate and multivariate analysis of risk factors and their association with anti-HEV IgG seropositivity among pregnant women in Medani, Sudan.

\begin{tabular}{|l|c|c|c|c|c|c|}
\hline & \multicolumn{3}{|c}{ Univariate Analysis } & \multicolumn{3}{c|}{ Multivariate Analysis } \\
\hline Characteristics & OR & $\mathbf{9 5 \%}$ Cl & P value & OR & $95 \%$ CI & P value \\
\hline Age & 0.9 & $0.92-1.07$ & 0.950 & 0.9 & $0.85-1.08$ & 0.572 \\
\hline Parity & 0.9 & $0.67-1.22$ & 0.525 & 1.3 & $0.85-2.07$ & 0.212 \\
\hline Gestational age & 0.8 & $0.7-1.08$ & 0.220 & 0.9 & $0.72-1.166$ & 0.492 \\
\hline Residence & 1.3 & $0.59-3.16$ & 0.351 & 0.6 & $0.20-1.79$ & 0.370 \\
\hline Educational level< secondary & 2.16 & $0.93-5.03$ & 0.072 & 3.1 & $0.89-10.82$ & 0.075 \\
\hline History of miscarriage & 1.83 & $0.72-4.64$ & 0.201 & 1.7 & $0.58-5.4$ & 0.308 \\
\hline Body mass index & 1.11 & $0.94-1.31$ & 0.205 & 1.1 & $0.95-1.45$ & 0.129 \\
\hline Hemoglobin & 1.44 & $1.00-2.08$ & 0.050 & 1.4 & $0.89-2.30$ & 0.137 \\
\hline
\end{tabular}

\section{Discussion and conclusions}

The main findings of the current study were: the high prevalence $(12.1 \%)$ of HEV IgG antibodies among pregnant women regardless of their age, parity, residence and educational levels. Recently Caron \& Kazanji (2008) found that $14.1 \%$ of 840 pregnant women in Gabon had anti-HEV IgG and the prevalence was significantly higher in the urban areas than in the rural ones (13.5 vs. $6.4 \%)$. Yet a much higher $(28.66 \%)$ HEV IgG seroprevalence was observed among Ghanaian pregnant women, especially pregnant women who were 21-25 years of age and women in their third trimester (Adjei et al., 2009). Furthermore, a high prevalence of HEV infection among pregnant women was reported in their neighboring countries, Egypt (84.3\%) (Stoszek et al., 2006), Ethiopia (59\%) (Tsega et al., 1993) and during an epidemic in Darfur, Sudan (31.1\%; Boccia et al., 2006). Interestingly a low (3.6\%) prevalence of anti-HEV IgG was reported in Iran and can be explained by the good hygiene and water supply in the investigated area (Rostamzadeh et al., 2013) and in Mexico (5.7\%), where pregnant women of advancing age were more likely to be seropositive for HEV IgG (Alvarado-Esquivel et al., 2014).

In the current study, two of the newborns showed a positive result for anti-HEV IgG. Recently, Mesquita et al. (2013) observed that four pairs (mother and newborn) of participants of the 12 pairs tested were seropositive for anti-HEV IgG. In Egypt, anti-HEV IgG was detected in $31 \%$ of 29 neonates with clinical suspicion of congenital infections (El Sayed Zaki et al., 2013). It is worth mentioning that although vertical HEV infection is common and can lead to a high neonatal mortality, HEV is a self-limiting infection in survivors with short-lasting viremia (Khuroo et al., 2009). 
Previously (2001), Kumar and colleagues reported 100\% transmission of anti-HEV IgG from the mother to the infant and suggested transplacental transmission of IgG. It has been recently demonstrated for the first time that HEV replication occurs in human placenta and that placenta is a proposed site of extrahepatic replication of HEV in humans (Bose et al., 2014). HEV is mainly transmitted by the fecal-oral route, zoonotic transmission from animal reservoirs (including donkeys) to humans, blood borne, human to human, and vertical transmission from mother to child have been reported (Mirazo et al., 2014).

The high seroprevalence of HEV amongst pregnant women in central Sudan may suggest that HEV may be widespread among pregnant women in the country as well as in the general population. Furthermore, because the virus is transmitted mainly through the fecal-oral route, sanitary and hygiene conditions should be in optimum conditions to reduce the risk of infection. Perhaps the policy of not screening for HEV antibodies in pregnant women in Sudan is based on the assumed low prevalence; screening for HEV should be employed based on the results of the current study. Moreover, antenatal screening of pregnant women would ensure that treating clinicians could take further precautions to protect against perinatal HEV transmission, minimizing the risk. One of the limitations of the current study is the failure to investigate the HEV genotyping which should be considered in the future study.

In summary, the current study revealed a high seroprevalence of HEV among pregnant women in central Sudan regardless of their age, parity and gestational age. Optimal preventive measures against HEV infection should be employed.

\section{Data availability}

F1000Research: Dataset 1. Raw dataset for Eltayeb et al., 2015 'Maternal and newborn seroprevalence of Hepatitis E virus at Medani Hospital, Sudan', 10.5256/f1000research.7041.d101652

Author contributions

RE - data collection, laboratory work, manuscript preparation. GIG study design, data analysis, and manuscript preparation. EME data collection, data analysis. HA - data collection, manuscript preparation. DAR - data analysis, manuscript preparation. IA study design, data analysis, and manuscript preparation. All authors have read and approved the final content of the manuscript.

\section{Competing interests}

No competing interests were disclosed.

\section{Grant information}

The author(s) declared that no grants were involved in supporting this work.

\section{Acknowledgements}

Authors would like to thank all the nursing and midwives staff of Medani Hospital, Sudan and the women who participated in the study.

\section{Supplementary materials}

\section{Supplementary file 1. Questionnaire administered to Mothers at the Medani Hospital, Sudan.}

After signing an informed consent form, socio-demographic, medical and obstetric characteristics were gathered using this questionnaire, translated from the local language (Arabic).

Click here to access the data.

Adjei AA, Tettey Y, Aviyase JT, et al:: Hepatitis E virus infection is highly prevalent among pregnant women in Accra, Ghana. Virol J. 2009; 6: 108 PubMed Abstract | Publisher Full Text | Free Full Text

Aggarwal R, Gandhi S: The global prevalence of hepatitis $E$ virus infection and susceptibility: a systematic review. Geneva, Switz: World Health Organization, 2010.

Reference Source

Ahmed RE, Karsany MS, Adam I: Brief report: acute viral hepatitis and poor maternal and perinatal outcomes in pregnant Sudanese women. $J$ Med Virol. 2008; 80(10): 1747-8.

PubMed Abstract | Publisher Full Text

Alvarado-Esquivel C, Sánchez-Anguiano LF, Hernández-Tinoco J: Hepatitis E

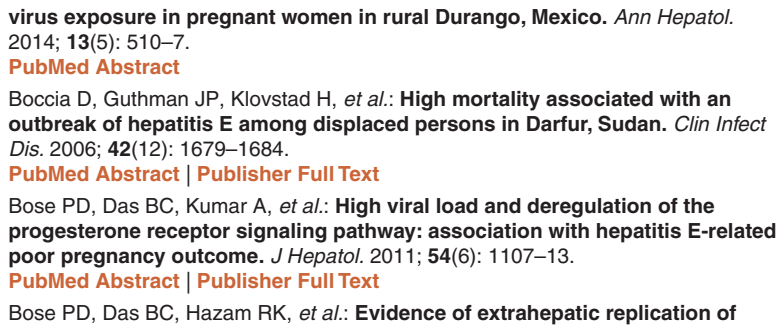

virus exposure in pregnant women in rural Durango, Mexico. Ann Hepatol. 2014; 13(5): 510-7.

PubMed Abstract

Boccia D, Guthman JP, Klovstad H, et al.: High mortality associated with an outbreak of hepatitis $\mathrm{E}$ among displaced persons in Darfur, Sudan. Clin Infect Dis. 2006; 42(12): 1679-1684.

PubMed Abstract | Publisher Full Text

Bose PD, Das BC, Kumar A, et al.: High viral load and deregulation of the progesterone receptor signaling pathway: association with hepatitis E-related poor pregnancy outcome. J Hepatol. 2011; 54(6): 1107-13.

PubMed Abstract | Publisher Full Text

Bose PD, Das BC, Hazam RK, et al.: Evidence of extrahepatic replication of 
hepatitis E virus in human placenta. J Gen Virol. 2014; 95(Pt 6): 1266-71. PubMed Abstract | Publisher Full Text

Caron M, Kazanji M: Hepatitis E virus is highly prevalent among pregnant women in Gabon, central Africa, with different patterns between rural and urban areas. Virol J. 2008; 5: 158.

PubMed Abstract | Publisher Full Text | Free Full Text

El Sayed Zaki M, El Aal AA, Badawy A, et al.: Clinicolaboratory study of motherto-neonate transmission of hepatitis E virus in Egypt. Am J Clin Pathol. 2013. 140(5): 721-6.

PubMed Abstract | Publisher Full Text

Eltayeb R, Gasim G, Elhassan E, et al.: Dataset 1 in: Maternal and newborn seroprevalence of Hepatitis E virus at Medani Hospital, Sudan. F1000Research. 2015.

Data Source

Khuroo MS, Kamili S, Khuroo MS: Clinical course and duration of viremia in vertically transmitted hepatitis $E$ virus (HEV) infection in babies born to HEV-infected mothers. J Viral Hepat. 2009; 16(7): 519-23.

PubMed Abstract | Publisher Full Text

Kumar RM, Uduman S, Rana S, et al:: Sero-prevalence and mother-to-infant transmission of hepatitis $E$ virus among pregnant women in the United Arab Emirates. Eur J Obstet Gynecol Reprod Biol. 2001; 100(1): 9-15.

PubMed Abstract | Publisher Full Text

Mesquita JR, Conceição-Neto N, Valente-Gomes G, et al: Antibodies to hepatitis E in Portuguese mothers and their newborns. J Med Virol. 2013; 85(8):

$1377-8$

PubMed Abstract | Publisher Full Text

Mirazo S, Ramos N, Mainardi V, et al:: Transmission, diagnosis, and

management of hepatitis E: an update. Hepat Med. 2014; 6: 45-59.

PubMed Abstract | Publisher Full Text | Free Full Text
Navaneethan U, Al Mohajer M, Shata MT: Hepatitis E and pregnancy: understanding the pathogenesis. Liver Int. 2008; 28(9): 1190-9. PubMed Abstract | Publisher Full Text | Free Full Text

Ornoy A, Tenenbaum A: Pregnancy outcome following infections by coxsackie, echo, measles, mumps, hepatitis, polio and encephalitis viruses. Reprod Toxicol. 2006; 21(4): 446-57.

PubMed Abstract | Publisher Full Text

Patra S, Kumar A, Trivedi SS, et al:: Maternal and fetal outcomes in pregnant women with acute hepatitis E virus infection. Ann Intern Med. 2007; 147(1): 28-33.

PubMed Abstract | Publisher Full Text

Rayis DA, Jumaa AM, Gasim Gl, et al:: An outbreak of hepatitis E and high maternal mortality at Port Sudan, Eastern Sudan. Pathog Glob Health. 2013; 107(2): 66-8.

PubMed Abstract | Publisher Full Text | Free Full Text

Rein DB, Stevens GA, Theaker J, et al.: The global burden of hepatitis $\mathrm{E}$ virus genotypes 1 and 2 in 2005. Hepatology. 2012; 55(4): 988-97.

PubMed Abstract | Publisher Full Text

Rostamzadeh Khameneh Z, Sepehrvand N, Khalkhali HR: Seroprevalence of hepatitis e among pregnant women in Urmia, Iran. Hepat Mon. 2013; 13(11): e10931.

PubMed Abstract | Publisher Full Text | Free Full Text

Stoszek SK, Abdel-Hamid M, Saleh DA, et al:: High prevalence of hepatitis E antibodies in pregnant Egyptian women. Trans Roy Soc Trop Med Hyg. 2006; 100(2): 95-101.

PubMed Abstract | Publisher Full Text

Tsega E, Krawczynski K, Hansson BG, et al:: Hepatitis E virus infection in pregnancy in Ethiopia. Ethiopia Med J. 1993; 31(3): 173-181.

PubMed Abstract 


\section{Open Peer Review}

\section{Current Peer Review Status: ? ? ?}

\section{Version 1}

Reviewer Report 22 August 2016

https://doi.org/10.5256/f1000research.7579.r15796

(C) 2016 Rajaram S. This is an open access peer review report distributed under the terms of the Creative Commons Attribution License, which permits unrestricted use, distribution, and reproduction in any medium, provided the original work is properly cited.

\section{Shalini Rajaram}

Department of Obstetrics and Gynaecology, Guru Tegh Bahadur Hospital, University College of Medical Sciences, New Delhi, Delhi, India

1. Hepatitis E Infection if it occurs in pregnancy can be acute, fulminant and fatal but mere presence of antibodies does not confer a risk like in Hepatitis B or Hepatitis C infection.

2. WHO - Presence of these antibodies does not imply presence of or increased risk of disease. The usefulness of such data for epidemiological purposes may also be limited due to variable and possible sub-optimal performance of available serological assays

3. It cannot be recommended for routine screening as suggested by authors.

4. Authors to reply as to what the 'AIM' of the study is and why did they choose this seromarker

Competing Interests: No competing interests were disclosed.

I confirm that I have read this submission and believe that I have an appropriate level of expertise to confirm that it is of an acceptable scientific standard, however I have significant reservations, as outlined above.

Reviewer Report 23 June 2016

https://doi.org/10.5256/f1000research.7579.r14088

(c) 2016 Spera A et al. This is an open access peer review report distributed under the terms of the Creative Commons Attribution License, which permits unrestricted use, distribution, and reproduction in any medium, provided the original work is properly cited. 


\section{Anna Maria Spera}

Department of Clinical Medicine and Surgery, Section of Infectious Diseases, University of Naples Federico II, Naples, Italy

\section{Vincenzo Bianco}

Department of Clinical Medicine and Surgery, Section of Infectious Diseases, University of Naples Federico II, Naples, Italy

In the current manuscript, authors reviewed the seroprevalence of $\mathrm{HEV}$ in mothers and newborns admitted at Medani hospital (Sudan): The paper addresses a very important issue, since there are few published data on the seroepidemiology on HEV infection in pregnant women and no one available from that country. However, some concerns should be addressed before its acceptance:

1. The English hasn't met the standard of publication and should be polished carefully;

2. The introduction section of this manuscript should be completed as follows:

Key facts about HEV infection should be added such as the geographical distribution ( currently available at the discussion section), transmission, virus life cycle, risk factors and protective factors which justifies the inclusions and exclusions criteria along with clinical findings (signs and symptoms, treatment and prevention). Nevertheless this is a study on seroprevalence of HEV infection, pointing out few information on the disease may improve the quality of the text;

The "aim" of the study which is the reason why authors have been decided to write the article, should be entitled and /or underlined. Furthermore, since the fact that the improvement of the sanitary and hygiene conditions along with the antenatal screening of pregnant women for HEV infection is a specific target of the work, as specified in the discussion section we would point out this outcomes even in the aim section of the paper 3. Moving on the Material and Methods section we suppose that it would be better to enlist the inclusion variables summarized in table 1 as long as the risks factors collected in table 2 . In addition, authors should describe better the way to gather data (questionnaire and blood samples collected from women along with the corresponding infants umbilical cord). Finally, would be better to express the age interval of pregnant women eligible for the study (not only the mean).

4. With regard to "discussion and conclusion section" we would divide it into two sub-sections. In the discussion, we would remove (or briefly summarize) the epidemiological data in order to focus on the transmission of the infection. As can be expected, we would better distinguish between the fecal-oral route and the vertical transmission of HEV. In fact the first one explain the overlap of pregnant women and general population affected by HEV infection: this may justify the necessity of improve sanitary and hygiene conditions; while the second one may explain the high prevalence of anti-HEV IgG in newborns that can lead to a high neonatal mortality and justifies the necessity of promoting antenatal screening of pregnant women in order to take further precautions to prevent perinatal HEV transmission.

Competing Interests: No competing interests were disclosed.

We confirm that we have read this submission and believe that we have an appropriate level 


\section{of expertise to confirm that it is of an acceptable scientific standard, however we have significant reservations, as outlined above.}

Reviewer Report 14 June 2016

https://doi.org/10.5256/f1000research.7579.r14346

(C) 2016 Borchardt S. This is an open access peer review report distributed under the terms of the Creative Commons Attribution License, which permits unrestricted use, distribution, and reproduction in any medium, provided the original work is properly cited.

\section{Stephanie M. Borchardt}

Wisconsin Immunization Program, Bureau of Communicable Diseases, Division of Public Health, Wisconsin Department of Health Services, Madison, WI, USA

Abstract

The title is appropriate for the content of the article and the abstract is a suitable summary of the work, though the last sentence of the abstract could include examples of "optimal preventive measures".

\section{Article Content}

Introduction: Whenever describing "prevalence rates" be clear whether or not it represents seroprevalence. Also, when referring to "anti-HEV antibodies" include whether it is in reference to IgM or IgG. If there is any information on duration of detectable IgM/IgG after infection with HEV it would be helpful to include it. Lastly, if there is information on clinical significance of HEV infection it would be helpful to include it. For example, with West Nile virus infection $90 \%$ will be asymptomatic, $10 \%$ will have West Nile fever and $<1 \%$ will have a more serious clinical course. And what is the clinical significance of a pregnant woman who is IgG positive for HEV and similarly her infant?

Materials and Methods: Please explain why mothers with diabetes or hypertension were excluded.

Table 1: Please clarify whether "haemoglobin, $g / d l$ " was significantly different $(p=0.008)$ between the two groups as the values (i.e., 9.9 vs. 10.4) appear to be very similar.

\section{Conclusions}

The fourth paragraph would be more appropriate for the introduction. More description is needed on "optimal preventive measures". The author suggests that pregnant women be screened prenatally for anti-HEV antibodies. Please clarify whether this would be for IgG or IgM. Screening for IgG would simply reveal whether or not the woman has ever been infected with HEV. To my knowledge there would be no transmission risk therefore please clarify the benefit of a prenatal screening program and what should be done for women found to be anti-HEV positive and infants born to them.

Competing Interests: No competing interests were disclosed. 
I confirm that I have read this submission and believe that I have an appropriate level of expertise to confirm that it is of an acceptable scientific standard, however I have significant reservations, as outlined above.

The benefits of publishing with F1000Research:

- Your article is published within days, with no editorial bias

- You can publish traditional articles, null/negative results, case reports, data notes and more

- The peer review process is transparent and collaborative

- Your article is indexed in PubMed after passing peer review

- Dedicated customer support at every stage

For pre-submission enquiries, contact research@f1000.com 